\title{
AGE TRENDS IN THE NEW ZEALAND AND AUSTRALIAN TRADES WORKFORCE 1991 TO 2001
}

\author{
Robert Haig \\ Work Opportunities \\ Department of Labour
}

\begin{abstract}
This paper reports on an investigation into the age profile of New Zealand trade workers. The research was undertaken after trades employers identified that ageing trends alongside skill shortages were a significant issue for their business future. The paper compares the age profile of NZ trades workers with the age profile of both the general NZ working population and that of Australian trades workers, drawing on occupational employment data from New Zealand and Australian censuses. It also looks at migration patterns among trade workers in New Zealand. The paper notes that New Zealand has been less effective than Australia in attracting, training or retaining young people in trades and this is a prime reason the New Zealand trade workforce was ageing faster than the Australian trade workforce in the '90s. The findings suggest that, as New Zealand already faces skills shortages in some trades, there is a risk that age-related attrition will add to this in the coming years.
\end{abstract}

\section{Introduction}

This paper investigates changes in the age profile of trades workers in New Zealand compared with Australia between 1991 and 2001. This information provides new insights into historic and future supply issues facing the trades, which is of some significance considering the current shortage of trade workers in New Zealand.

\section{Background}

The impetus for this research came from the Job Vacancy Monitoring Programme (JVMP), an initiative of the government's Skills Action Plan designed to give new insights into skill shortages, which is run by the Department of Labour (DOL). One of its components is an intensive, largely qualitative survey (SERA Intensive) of employers who have recently advertised vacancies in selected skilled occupations. I During interviews conducted in 2004 as part of the JVMP, some employers in traditional trades such as metalworkers and carpenters told Department of Labour (DOL) that, alongside the widely reported issue of skills shortages, they were grappling with the issue of an ageing workforce. In particular, many trades employers spoke of a long-term decline in the number of younger people entering the trades. Ageing trends are undoubtedly having a strong influence across the overall New Zealand workforce. In the mid-1980's, the mid-point of the population was under 30, and now the mid-point is over 35 and rising. The proposition that this ageing was particularly rapid in trades was investigated through an analysis of census data from both New Zealand and Australia.

Australia was chosen as a comparison to see if there was an ageing issue with the trades workforce in general. Many of their trades are similar in terms of type of work, level of training required, and in work and non-work cultural similarities. Their official occupational classifications are also broadly similar.

In terms of demand, the two countries also faced many similar influences in the 1990's. These include a recession in the early part of the decade, accompanied by structural adjustments to improve competitiveness, as well as trends such as growth in labour outsourcing within some trade- dominated industries such as construction. It should be acknowledged however, that Australia perhaps experienced less structural adjustment and experienced an increase in its trade employment by about $4 \%$ over this decade, whereas trade employment levels were more static in New Zealand. Trades have decreased their share of total employment over this time in both countries.

\section{Methodology}

To investigate this issue, three exercises were conducted:

Using data from the last three New Zealand population censuses (1991, 1996 and 2001) the changing age profile of trades workers was contrasted with the changing structure of the total New Zealand workforce.

Australian Population Census data from the same period was looked at to determine if any similar changes in age profile had occurred amongst their trades population.

External migration data was investigated to see if migratory patterns could have contributed to a changing age profile.

Information was taken from each country's respective 1991, 1996 and 2001 Censuses covering all people in employment on census night (both part-time and fulltime) excluding temporary residents. The census data was grouped into standard 5-year age bands. New Zealand trades workers were defined as those recorded in 
the New Zealand Standard Classification of Occupations (NZSCO) 1999 code 7 "Trades workers". Australian trades occupations came from those in the Australian Standard Classification of Occupations (ASCO version 2) Group 4 "Tradespersons". Both cover a large and diverse range of trade occupations, within a range of industries such as the building, metalworking, electrical and automotive industries.

In order to make a more valid comparison, it was necessary to remove some Australian trades groupings from ASCO version 2 that did not fall under the NZSCO group 7. The largest of these exclusions included:

\section{Cooks}

\section{Green keepers}

\section{Gardeners}

\section{Hairdressers}

\section{Defence Force Members}

4992 Performing Arts Support Workers

After these exclusions, the total size of the Australian trades workforce comprised about 840,000 people in the 2001 census compared to about 145,000 New Zealand trades people. (See Table 3, Summary of changes by age group).

Figure 1: Usually Resident Working NZ Population by Age Group 1991- 2001

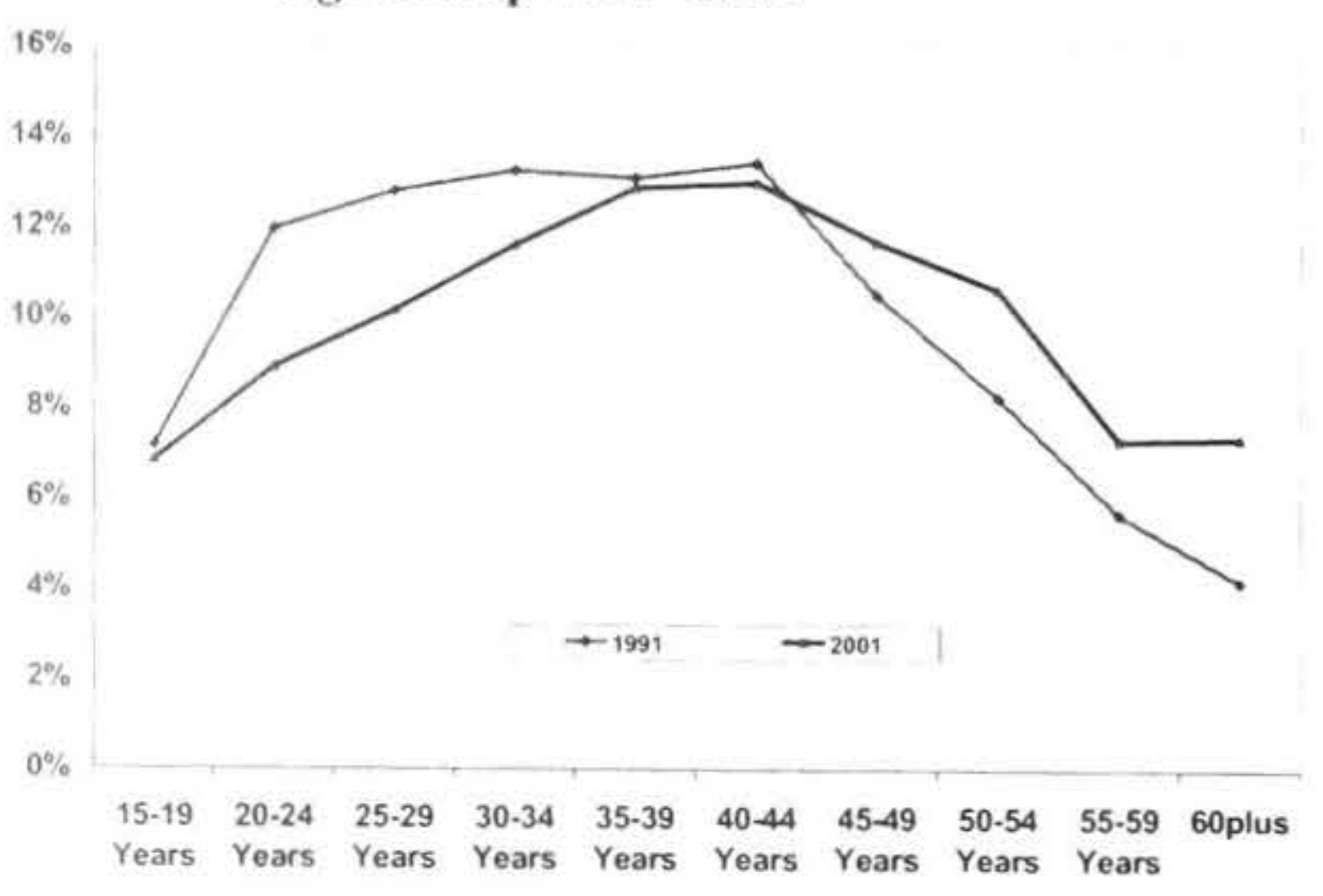

\section{New Zealand Working Population Compared with New Zealand Trades Population}

Figure I shows the changes in age distribution in the usually resident working population in New Zealand between the 1991 and 2001 census.

In 1991, about 7\% of the New Zealand working population were aged 15-19 years old, 12\% were aged 20-24 years, 13\% were aged 25-29 years, and the peak age group was the 40-44 years age group, at just under $14 \%$
By 2001, there was a widespread ageing trend, with falling proportions in younger age groups and higher proportions in older age groups. For instance, the percentage of all employed aged 20-24 fell from about $12 \%$ to about $9 \%$ over this period.

Overall growth in labour force participation among older New Zealand workers across all occupation groups has resulted in an increasing proportion in the older age groups, especially 60 years and over. New Zealand policy changes strongly influenced this, with the age at which people are eligible to receive superannuation being progressively raised from 60 to 65 between 1992 and 2001. This, plus the removal of retirement age limits, encouraged more people to continue their working careers.

Figure 2: NZ Trades Age Profile 1991-2001

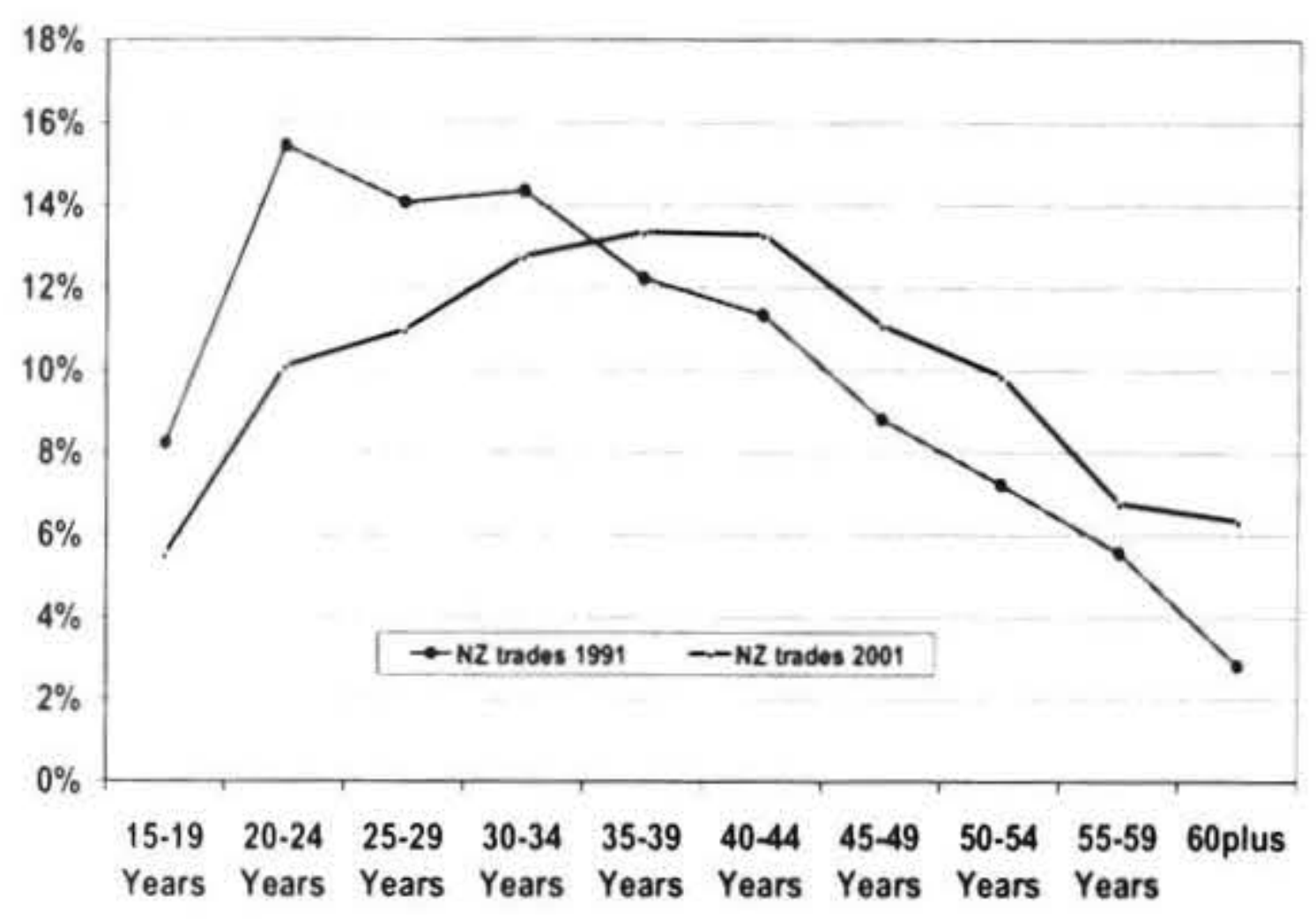

Figure 2 shows the change in age distribution for New Zealand tradespeople only, over the same period.

In 1991 it was more skewed towards the younger age groups than the national picture, but this difference was much less apparent by 2001 .

In 1991, $8 \%$ of New Zealand trades workers were $15-19$ years old, $16 \%$ or one in six were aged $20-24$ years which was the peak age group, about $14 \%$ were aged 25 29 and a steadily decreasing proportion were in older aged groups, ending with about $3 \%$ aged 60 or over.

By 2001, the proportion in the first three 5-year age groups had fallen away sharply, compensated by rises in the proportion in older age groups. The combined under 40 years age group's share of the total trades workforce fell sharply from 64 percent to 53 percent, ( 11 percentage points).

The peak age group had moved to $40-44$ years, the same as the highest age group across all occupations.

To indicate which broad category of trades workers has aged the most, these are the increases in mean age between 1991 and 2001:

- $\quad$ Electricians 4.9 years

- Metalworkers 4.6 years 
- $\quad$ Building Finishers (e.g. plumbers) 3.1 years

- Building Frame workers (carpenters and builders) 2.6 years

\section{- Working Population 2.5 years}

Therefore, electricians, closely followed by metalworkers, have aged the most.

Figure 3 gives a graphic example of one of the sharpest falls in the number of young people in one of the occupation that makes up the Trades metalworkers group, fitter and turners (NZSCO 72231). The number aged 1524 fell from 1,590 in 1991 to 320 in 2001 .

\section{Figure 3: Decline in Younger (aged 15-24) Fitters and Turners}

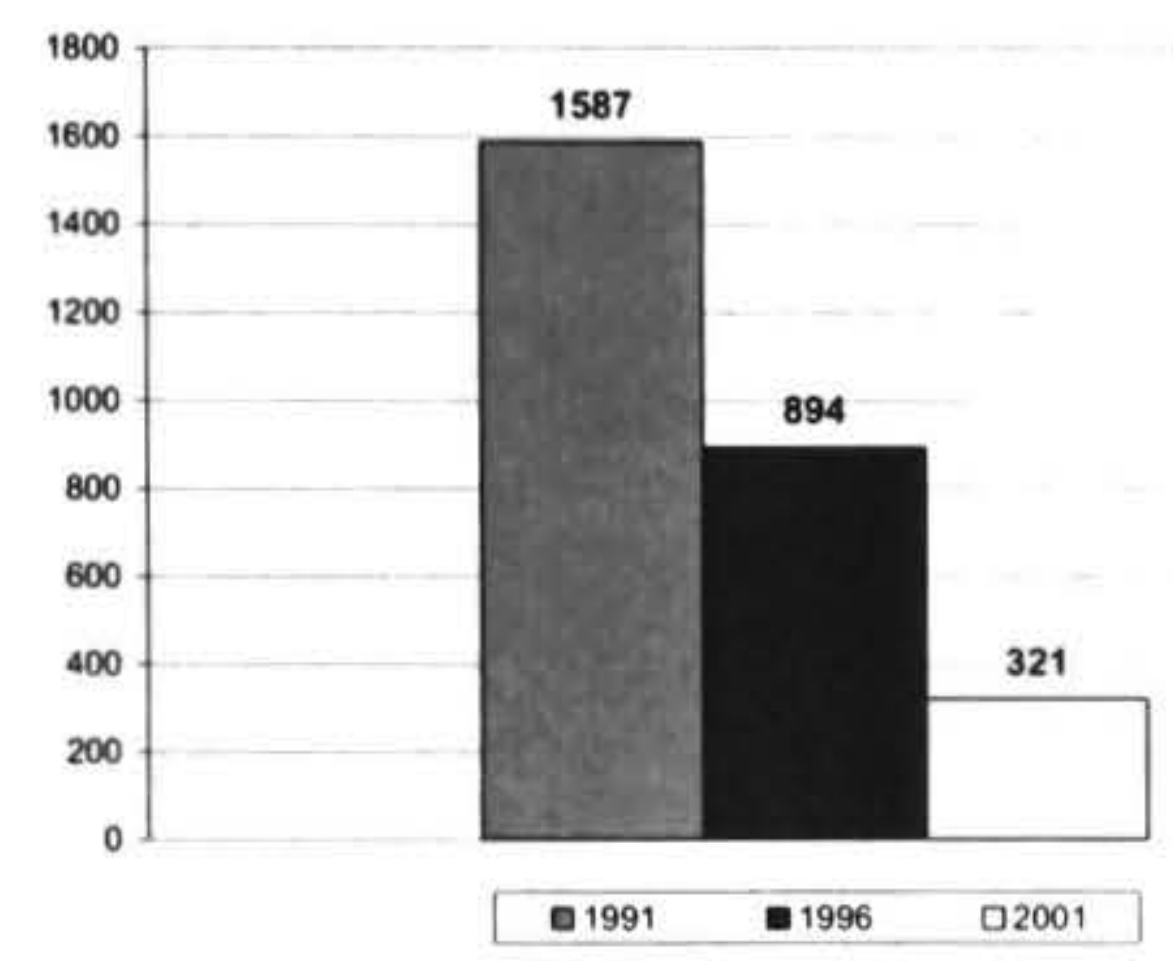

\section{New Zealand Trades Compared with Australian Trades}

It is interesting to see whether Australian trades have shared the NZ trades ageing trend. Australia's trades age profile looked similar to New Zealand's in 1991, (Figure 4). Their largest single age group was the 20-24 years group, which accounted for $16 \%$ of their trades workforce - the same proportion as it was in New Zealand.

\section{Figure 4: Australian Trades Workers Age Profile 1991-2001}

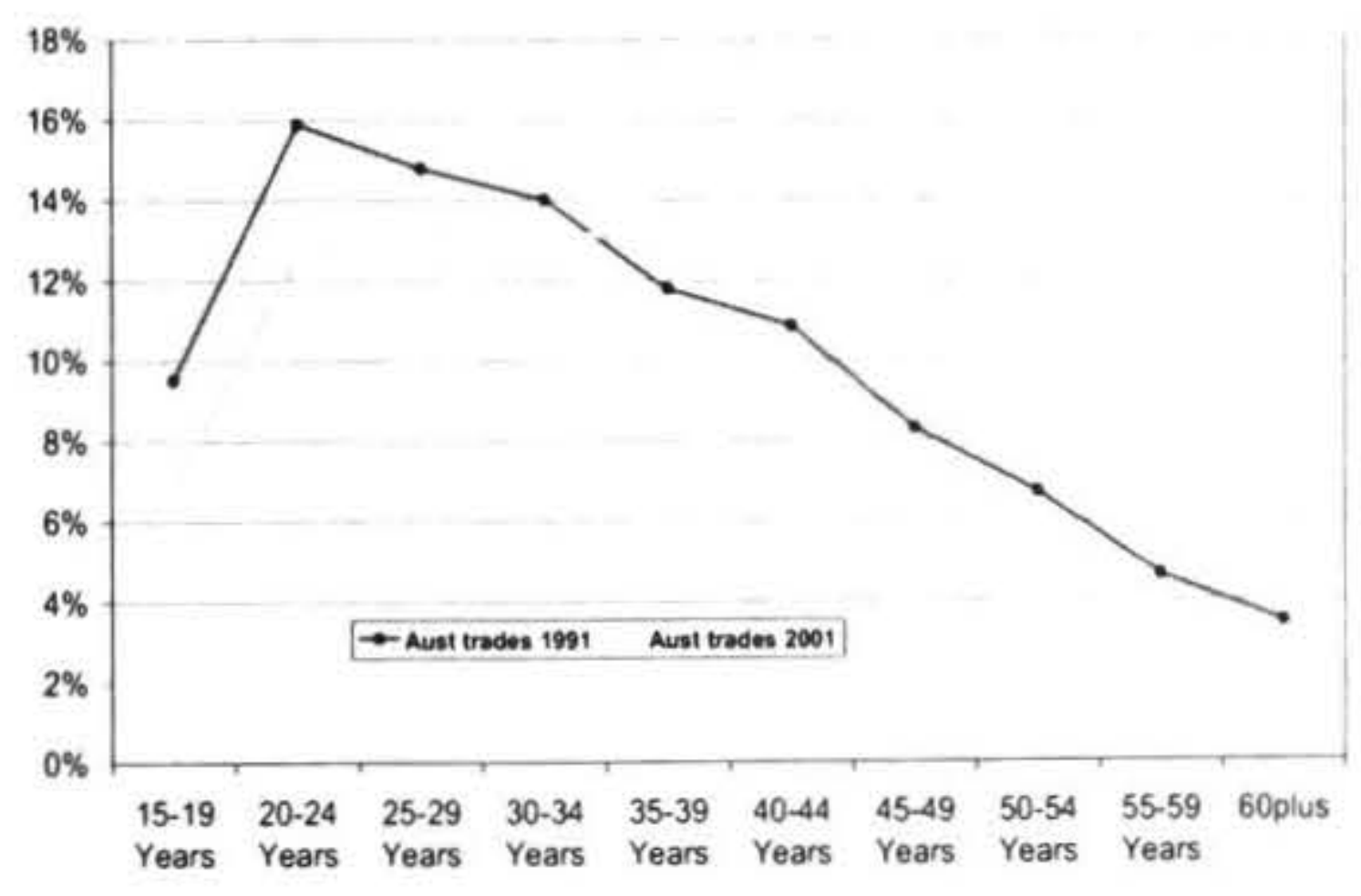

By 2001, Australia had also experienced a fall in the proportion of younger aged people in trades, so this trend is certainly not unique to New Zealand trades workers.
However, the overall shape of the age distribution shows that Australian trades workers have not aged by as much, especially in the younger age groups. Their age distribution flattened out a little, but kept its 1991 shape more closely than the New Zealand age distribution. For instance, the population aged 20-24 fell from about $16 \%$ to $13 \%$ whilst for New Zealand trade workers the fall was from $16 \%$ to $10 \%$. The largest single Australian trades group is the $30-34$ years age group whereas New Zealand's largest single age group is a decade older (aged 40-44 years).

Grouping the under 40 year age bands together, their share of the total trades workforce fell from 66 percent down to 59 percent between 1991 and 2001, which is a more moderate decline than the 11 percentage point decline experienced amongst that age group in New Zealand Trades workers over the same period.

Australia also does not show our large increase in working trades people aged 60 plus. However, this reflects the fact that Australia's proportion of older people in work (their participation rate) has not risen to the extent New Zealand's has over this period.

\section{Table 1: Ratio of Younger Trades Workers to those Aged 55 plus}

\begin{tabular}{|l|c|c|}
\hline & New Zealand & Australia \\
\hline 1991 & 2.8 & 3.1 \\
\hline 1996 & 2.0 & 2.8 \\
\hline 2001 & 1.2 & 2.0 \\
\hline
\end{tabular}

Table 1 shows the number of trades workers approaching retirement (aged 55 plus) compared to those younger trades entrants (aged 15-24), expressed as a ratio. In the New Zealand trades workforce, the dynamics have changed quickly between 1991 and 2001. The number of younger persons in work to every older person has decreased from 2.8 to 1 down to 1.2 to 1 . This is now close to New Zealand's overall ratio of younger to older employed, which was 1.1 to 1 in 2001 .

In comparison, Australia began with a similar (3.1 to 1) ratio in 1991 and ten years later had experienced a more gradual decline to a 2 to 1 ratio. Although this is also approaching its national ratio of 1.4 to 1 , the change has been less pronounced.

Of course there are greater variations in certain occupations. Among New Zealand plumbers, for example, the 55 plus age band now exceeds the size of the under $25 \mathrm{~s}$, which is in stark contrast to the picture in that group in Australia.

Table 2 demonstrates in numeric terms the declining proportion of younger tradespeople to older tradespeople. In New Zealand, the number of younger trades workers aged 15-24 has declined by more than one third, from 35,349 to 23,000 while the number of those aged 55 and over has increased strongly by about 50 percent from 12,500 to 19,000 . 
Table 2: Number of Younger and Older Tradespeople 15-24 years

\begin{tabular}{|c|c|c|}
\hline & New Zealand (000) & Australia(000) \\
\hline 1991 & 35 & 205 \\
\hline 1996 & 29 & 186 \\
\hline 2001 & 23 & 168 \\
\hline
\end{tabular}

\begin{tabular}{|c|c|c|}
\hline & 55 + years \\
\hline 1991 & 12 & Australia(000) \\
\hline 1996 & 15 & 65 \\
\hline 2001 & 19 & 83 \\
\hline
\end{tabular}

Australia has had a more gradual decline in younger trades workers, with numbers falling from 205,000 to 168,000, (about $17 \%$ ). The number of Australian older aged trades workers also increased at a more gradual rate, from 65,000 to 83,000 .

Interestingly, although Australia has preserved a higher share of 15-24 year olds in its trade employment than New Zealand, some Australian reports have also expressed concern at the fall in training rates in areas such as metal, construction and electrical trades. This decline may in part be due to the impact of the severe recession in the early 1990's and the restructuring that followed.

\section{Impact of Immigration on Trades Age Profiles in New Zealand}

Many different factors can affect the numbers entering or leaving an occupation and thereby affecting age structure. These include training and wastage levels- the numbers flowing into or out of trade jobs into non-trade jobs, or into and out of the workforce entirely. Figure 5: NZ Net Trades Migration by Broad Age
Band

$\begin{array}{lllllllllllll}1992 & 1993 & 1994 & 1995 & 1996 & 1997 & 1998 & 1999 & 2000 & 2001 & 2002 & 2003 & 2004\end{array}$

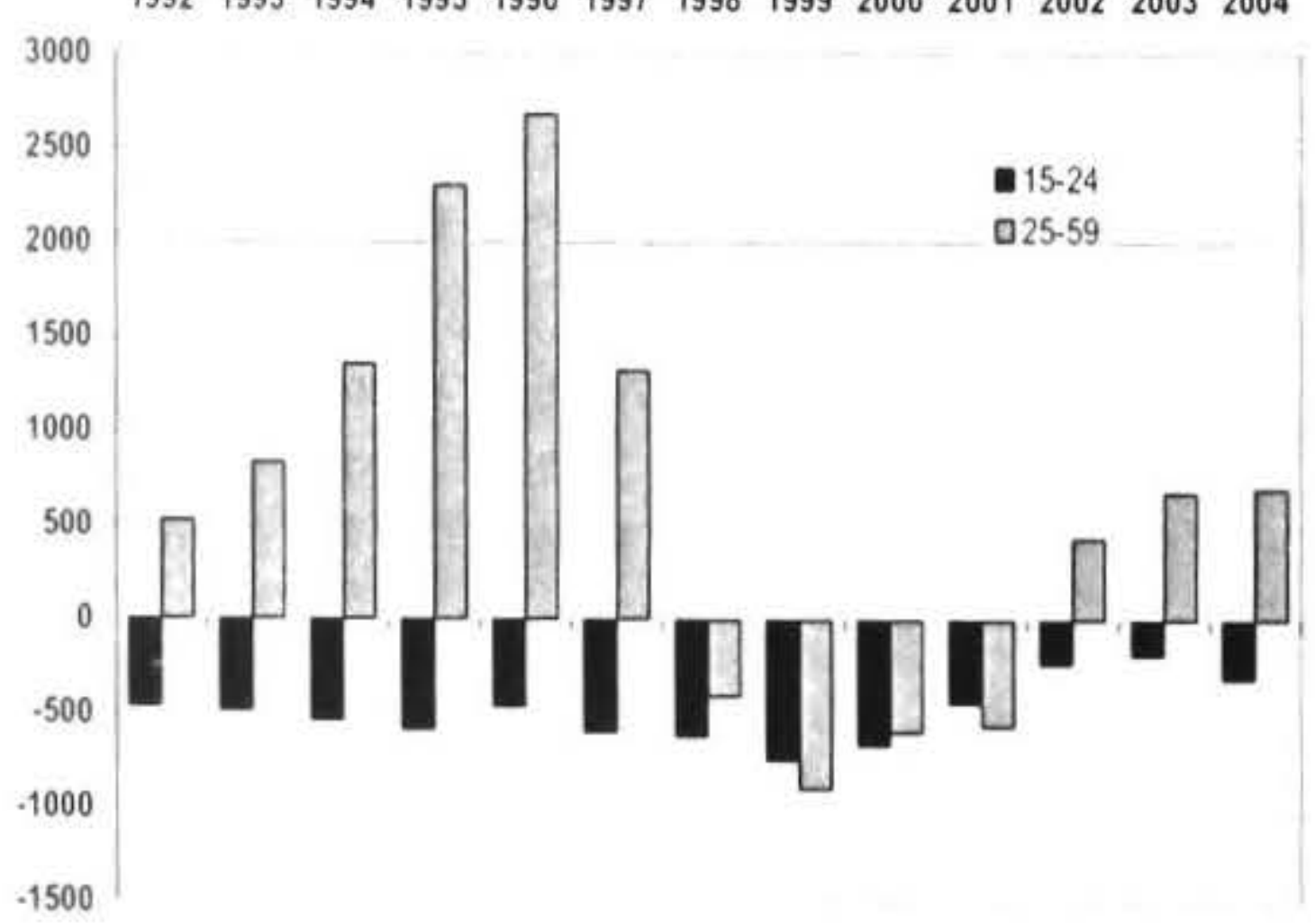

External migration is one area that impacts on the age structure of trades workers. Figure 5 shows annual net migration flows for trades workers in each June year (i.e., migrant inflows minus migrant outflows), split between net migration of those aged 15-24 (in the darker bars) compared with those aged 25-59 (the lighter bars).

In total, we had a modest overall net gain of fewer than 1,000 trades workers between June 1991 and June 2001, or 100 new trades people per year.

For the younger trades people, (those aged under 25), net outflows have occurred in every year, even when the domestic economy has been strong. Note this may be a fixed pattern (i.e. the traditional "OE" effect) and therefore on its own would not explain any of the decrease amongst younger age groups between 1991 and 2001.

The 25-59 years band, however, appear more responsive to labour market improvements than the younger age groups. There were very strong net inflows when the economy was buoyant in the mid-90s, followed by four years of net outflows from 1997 to 2001. Since then, net inflows have resumed as the economy strengthened.

Therefore, while overall net migration has contributed little to total New Zealand trades supply over this period, it probably has contributed to an older trades workforce due to outflows of younger workers being replaced with older ones (or perhaps returning New Zealand trades workers) in the mid-1990s. It is also notable that even when there is a net inflow of trades people to New Zealand, (such as in the last 3 years), we tend to have a negative rate of exchange in trades workers with Australia. Australia in fact achieves considerable net gains in trades workers through migration - studies there by Philip Toner shows it gains the equivalent of $14 \%$ of all its new trades apprentices through net migration. Comparable figures for New Zealand are currently unavailable but would appear to be lower.

\section{Conclusions}

In conclusion, census results appear to support general concerns about an ageing trades workforce in New Zealand. Although the age profile among trades people increased on both sides of the Tasman in the period covered, New Zealand trades workers have aged more quickly. Our trades age profile used to be aligned with Australia's trades age profile, but is now less closely aligned.

Looking at specific age groups, we can see that New Zealand trades workers lost a relatively larger share of their workforce aged 15-24. This suggests problems in attracting, training and retaining younger people over this period. There have also been higher falloffs in the proportion who are in the 25-39 year age bands compared to Australia. (See Table 3).

Some general reasons for this comparatively rapid ageing amongst the New Zealand trades workforce include:

- A lower inflow of young people into trades reflecting reduced apprentice intake. 
- A general "drift" away from trades as a career among younger people.

- Rapid structural change in New Zealand industries employing the bulk of trades workers (such as manufacturing and construction).

- Net migration losses amongst younger New Zealand tradespeople compensated by inflows of those in higher age groups.

\section{Implications}

If the plumber who comes to fix your drain nowadays seems a little older, does this really matter?

- It may have no effect on productivity, i.e., older workers often have greater experience, skills and knowledge of how to use them in the workplace.

- It is unlikely to result in higher injury/accident rates. According to injury claim data, injury claim rates for males less than 35 are higher than in older age groups - so it may contribute to a fall in the injury rate.

- In addition, potential trades recruits now have wider career choices than ever before and may find better opportunities to be more productive elsewhere in the economy.

Up to now, the effect of fewer youth inflows on skill shortages has probably been cushioned to some extent by older age groups tending to stay in work for longer. (This does not appear to be occupation related, but reflects an overall pattern of higher participation amongst older age groups in NZ due to retirement changes). However, in future, an older workforce means increased likelihood of age-related attrition as a growing proportion of skilled workers retire or cut back their working hours. Furthermore, these retirements may occur at a time when strong increases in demand for trades labour are still being experienced.
Demand growth for trades has been very strong in the past few years, with the construction industry being a good example of this. The sustained, three-year growth in construction activity has resulted in very large employment growth of $31 \%$ in this sector in the three years to June 2004, according to Household Labour Force Survey data. Few technological improvements or economies of scale are available to respond to demand growth in this sector so, for example, an extra increment of trades labour is required for every new house. In the face of these demand increases there appears to be little spare capacity in the trades workforce at present. DOL research reports show evidence of severe skill shortages in a number of trades occupations.

The persistence of strong demand combined with an ageing trades population means supply is becoming more vulnerable. DOL plans to use the useful insights from this investigation in policy development and in discussions with the trades sector.

\section{Future Research}

Australian and New Zealand statistical authorities are more closely integrating their occupation classifications (using the ANZSCO code) and the changes will be implemented in time for the 2006 census. This will increase the scope for making more in-depth transTasman occupational comparisons, enabling changes in New Zealand occupations to be put into a wider Australasian context. This will open up new avenues for further research into common or unique aspects of these two labour markets.

Further investigations of the interaction between skill shortages, labour constraints and the ageing workforce could well be of use in other sectors of the economy, to assist in more clearly understanding the pressures and constraints in different industries and the potential strategies and solutions to overcome them.

Table 3: Summary of Changes by Age Group: New Zealand Trades NZSCO level 7 Compared with Equivalent Australian Trades Categories.

\begin{tabular}{|llccccc|}
\hline \multicolumn{7}{c|}{ Age Group } \\
\hline $\mathbf{1 9 9 1}$ & & $\mathbf{1 5 - 2 4}$ & $\mathbf{2 5 - 3 9}$ & $\mathbf{4 0 - 5 4}$ & $\mathbf{5 5}$ Plus & Total \\
\hline NZ & Number & 35349 & 60696 & 40869 & 12516 & 149430 \\
\hline & Percent & $24 \%$ & $41 \%$ & $27 \%$ & $8 \%$ & $100 \%$ \\
\hline Australia & Number & 204756 & 327163 & 208659 & 65281 & 805859 \\
\hline & Percent & $25 \%$ & $41 \%$ & $26 \%$ & $8 \%$ & $100 \%$ \\
\hline & & Age Group & & & \\
\hline $\mathbf{2 0 0 1}$ & & $\mathbf{1 5 - 2 4}$ & $\mathbf{2 5 - 3 9}$ & $\mathbf{4 0 - 5 4}$ & $\mathbf{5 5}$ Plus & Total \\
\hline NZ & Number & 22662 & 53850 & 49737 & 19047 & 145296 \\
\hline & Percent & $16 \%$ & $37 \%$ & $34 \%$ & $13 \%$ & $100 \%$ \\
\hline Australia & Number & 162933 & 329179 & 264092 & 81853 & 838057 \\
\hline & Percent & $19 \%$ & $39 \%$ & $31 \%$ & $10 \%$ & $100 \%$ \\
\hline
\end{tabular}




\section{Notes}

1. For full details of this programme, see LEW 11 Conference paper "The Department of Labour's Job Vacancy Programme" by Andrew Whiteford.

\section{References}

Bob Birrell, Ian R Dobson, Virginia Rapson and T. Fred Smith (2001). Skilled Labour: Gains and Losses - Australian Immigration Research Centre for Population and Urban Research, Monash University
Department of Labour, (2004). People power Successful diversity at work. Publication available on-line at www.dol.govt.nz

Newell, J and Perry, M. (2004). (Draft paper) The Changing Structure of New Zealand Occupations 1991 to 2001.

Toner, P (2003). Supply Side and Demand Side Explanations of Declining Apprentice Training Rates: A Critical Overview. Australian Journal of Industrial Relations, 45, December 2003.

Whiteford, A. (2004). JVMP: An Overview, Proceedings of the $11^{\text {th }}$ LEW Conference. 